\title{
NUEVAS PERSPECTIVAS SOBRE LA INQUISICIÓN ESPAÑOLA
}

En 1967 se publicó mi estudio sobre la Inquisición española; desde entonces, el tema ha tomado proporciones de investigación industrial. Buena parte del interés actual en la materia se debe a los trabajos de Julio Caro Baroja sobre los conversos, la brujería en Navarra y la personalidad de los inquisidores. Mucho han explorado desde esa época especialistas y estudiantes. Un panorama excelente se encuentra en el número especial de Historia-16 (Madrid, 1976) dedicado a la Inquisición (en el que colaboré), y en el que se encuentran entre otros, artículos de Caro Baroja, Marcel Bataillon. En 1978 se realizó en Cuenca un seminario que reunió especialistas interesados en el tema, y en estos momentos se preparan otras reuniones.

Toda esta actividad, aunque parezca extraño, aumentó muy poco nuestro conocimiento sobre la Inquisición. Henry Charles Lea, en su extraordinario trabajo de cuatro volúmenes (1906. 1908), llegó a conclusiones que nunca fueron refutadas, y es difícil que sean superadas. Los investigadores actuales no se dedican, como los del siglo XIX, al estudio de instituciones. Por otra parte, las bases sólidas que puso Lea nos han permitido dirigirnos a nuevas fronteras. Un ejemplo valioso de nuevos trabajos es el de Ricardo García Cárcel, sobre la historia completa de un solo tribunal, el de Valencia, desde su origen hasta 1530. En un segundo volumen esa historia se inicia en 1530 y termina en 16091 .

Como muchos especialistas modernos, García Cárcel se interesa en la Inquisición no como institución, sino como parte fundamental de la sociedad y política valencianas. Su libro, por lo tanto, busca dimensiones diferentes de las que interesaban a Lea. En tres secciones maestras, concisas, lúcidas, Cárcel explora las relaciones de la Inquisición con la vida de los valencianos

1 Ricardo Garcia Cárcel, Herejía y sociedad en el siglo xvi. La Inquisición de Valencia, 1530-1609, Ediciones Península, Barcelona, 1980. 
durante el tempestuoso siglo XVI. Como era inevitable, la función de los moriscos era muy importante, aunque, en realidad, el número de moriscos juzgados por la Inquisición fue relativamente bajo: 3000 entre 1518 y 1609; de éstos, 25 fueron condenados a muerte.

Más que la represión física, era importante la represión moral a la cultura morisca. Louis Cardaillac ha dedicado al tema un valioso estudio; García Cárcel lo hace también. La Inquisicón era, por lo general, más tolerante con los moriscos de lo que nunca fue con los conversos; sólo se endureció en una súbita reacción impaciente en la represión de los años 1589-1592.

El tribunal no se ocupaba solamente de minorías raciales. García Cárcel dedica páginas contundentes al luteranismo en Valencia: "se encuentran pocos luteranos autóctonos del país... El luteranismo valenciano fue superficial y pragmático, con escasa cobertura teológica y sobre todo verbalista".

García Cárcel dedica un tercio de su libro a lo que llama "contracultura" en Valencia, es decir, a aquellas infracciones contra el pensamiento oficial y a las prácticas sexuales establecidas. Hay en el libro una sección muy interesante en la que el autor analiza la posible influencia de la Inquisición en la castellanización de Valencia, pero llega a la conclusión de que el tribunal es inocente en este caso: "casi todos los procesos hasta 1540 - dice - están escritos en catalán. Coacción idiomática no hemos visto reflejada en ningún interrogatorio". Este trabajo de García Cárcel se encuentra entre los más importantes que se hayan escrito sobre la Inquisición española en los últimos cincuenta años.

Bartolomé Bennassar y los alumnos que trabajaron con él adoptaron un método diferente para estudiar la Inquisición ${ }^{2}$. Bennassar colaboró con el erudito danés Gustav Henningsen ${ }^{3}$ y el historiador Jaime Contreras para conseguir un método estadístico. Henningsen anunció un programa para contar y analizar todo el material de la Inquisición; su fuente principal son las "Relaciones de Causas" que se encuentran en el Archivo Histórico Nacional de Madrid. El libro de Bennassar sigue de cerca esta práctica; en el primer capítulo, por ejemplo, presenta

2 BARTOlomé BenNASSAR, L'Inquisition espagnole xvexix siècle, Hachette, Paris, 1979.

3 Gustav Henningsen, "El 'banco de datos' del Santo Oficio. Las Relaciones de Causas de la Inquisición española (1550-1700)", $B R A E, 174$ (1965), 547-572. 
estadísticas completas de todos los juicios que se hicieron en el tribunal de Toledo a través de su historia.

El libro no es puramente estadístico. Es una buena investigación, muy inteligente y accesible a la lectura. Hay un buen capítulo de Marie-José Marc que trata sobre una villa morisca que encontró en Extremadura, y tres capítulos excelentes de Jean-Pierre Dedieu sobre moral y herejía. Pero la preocupación básica es su contenido cuantitativo. Ahora bien, los datos cuantitativos pueden ser valiosos para los historiadores, pero deben definirse e interpretarse con cuidado para no caer en errores. Hay algunos problemas con la información inquisitorial que me hace dudar de que el método que usan Bennassar, Henningsen, Dedieu, Contreras y otros, dé buenos frutos.

Me explico: en primer lugar, las Relaciones de Causas en las que Henningsen y Contreras se apoyan para obtener sus series estadísticas están a menudo incompletas, y apenas cubren un período que va aproximadamente de 1550 a 1700. Las Relaciones ofrecen información valiosa para ese período, pero aun así pueden inducir a error. Bennassar, por ejemplo, dedica doce páginas a detallar estadísticamente la actividad del tribunal de Toledo, y demuestra que esa actividad decayó profundamente desde mediados del siglo XVII; pero en ningún lugar de esas doce páginas menciona Bennassar un dato utilísimo: que muchas de las tareas que tenía a su cargo el tribunal de Toledo se traspasaron hacia 1650 a un nuevo tribunal de Madrid.

En segundo lugar, la cuantificación de los casos de "curvas de actividad", significa que cada caso tiene el mismo peso, y no se intenta distinguir entre hechos importantes y triviales. Las gráficas elaboradas a base de esta información muestran que el nú . mero de individuos juzgados por blafemia y proposiciones, era, probablemente, veinte veces mayor que el de aquellos juzgados por protestantismo. Esta información deforma, por un lado, la relativa importancia de la blasfemia y el protestantismo, por otro, confunde dos tipos diferentes de juicios, puesto que las denuncias por blasfemia las hacían, generalmente, gente común, y el Santo Oficio no las alentaba. Pero los procesos contra protestantes se debían invariablemente a las activas campañas instigadas por la Inquisición.

En tercer lugar, para cuantificar los casos es necesario clasificarlos, y tengo serias dudas sobre la clasificación hecha por Henningsen. Miles de los que arrestaba la Inquisición eran acusados por múltiples faltas, pero el método de Henningsen las agruparía en un tipo u otro. ¿Cómo clasificaría Henningsen, por ejemplo, a 
un reo acusado a la vez de proposiciones blasfemas, de juramentos contra la Inquisición, y de declaraciones de que la fornicación no es pecaminosa? No me parece acertado afirmar que se está haciendo un análisis científico de los miles y miles de casos juzgados por la Inquisición, y luego adoptar un método de clasificación que no es exacto en absoluto. García Cárcel ha señalado ya que según el método de Henningsen algunas desviaciones sexuales tienen categoría propia (tentativa de seducción en el confesionario, bigamia), pero otros, tales como fornicación, homosexualidad, bestialidad, simplemente se clasifican en "varios".

En cuarto lugar, el problema más grave que provoca una cla. sificación inadecuada es que Henningsen no puede distinguir con su método entre el luteranismo supuesto y el verdadero. En el libro de Bennassar (p. 280), Jean-Pierre Dedieu presenta dos gráficas (de "luteranos juzgados por la Inquisición"). Según estos datos, en Barcelona, Zaragoza, Toledo y otras áreas, durante el decenio de 1560, existían aún centros de actividad luterana; ya que sabemos que esas localidades no eran centros de esa clase, podemos suponer que las gráficas estadísticas están mal o que, en último caso, pueden inducirnos a error. Dedieu reunió a todos aquellos acusados como luteranos, y nos ha dado un panorama de la actividad inquisitorial que de ninguna manera se relaciona con la verdadera influencia de Lutero en España.

En resumen, el libro de Bennassar es un buen estudio erudito que atraerá la atención sobre el tema. Sin embargo, al poner el acento en la cuantificación, quizá se empiece por hacer preguntas equivocadas para terminar consiguiendo respuestas equivocadas. Las funciones de la Inquisición no pueden medirse sólo por el número de sus causas de fe. El trabajo que han hecho Henningsen y otros, es, sin duda, necesario, pero es ilusorio pen. sar que no haya problemas en su interpretación.

HENRY KAMEN

University of Warwick. 